(and in what circumstances) the investment may be worthwhile. That amounts to a further plea for a better public understanding of science - one that illustrates the financial and economic hazards of continued ignorance.

\section{Honorary authorship}

A case of fraud at a London hospital points to the need for a ban on honorary co-authorship in the literature.

THE British, who are given to self-contentment bordering on smugness, are fond of saying that fraud in science does not happen in what Shakespeare called "this scepter'd isle" (chosen as the title of a new 200-part series on BBC radio). After last week, they will no doubt be claiming that part of the explanation is that the penalties for being found out are severe and swift: last week, the British Medical Council "struck off" the national medical register (or delicensed) a physician who had falsely claimed to have transplanted an ectopic pregnancy from its aberrant position to the uterus of the woman concerned, and that the fetus had developed normally and had been delivered successfully (see Nature $372,390 ; 1994)$. The evidence given last week appears to have been convincing, but Dr Malcolm Pearce says he will appeal against the council's findings and decision.

Certainly the British case, which first came to light six months ago, has been handled more swiftly than the US case of Dr Thereza Imanishi-Kari. She has been accused by the US National Institutes of Health of fabricating data in a paper published nine years ago and whose best-known author is Dr David Baltimore. By coincidence, her appeal is being heard this week in Washington, DC, by an administrative tribunal of the Department of Health and Human Services. Imanishi-Kari has been on the research community's equivalent of death row for much too long. Everybody, for a variety of reasons, will agree on that. But it is also possible that the British case has been too swiftly, or too unreflectively, decided.

The circumstances betoken muddled principles. The offending Pearce paper was published in the British Journal of Obstetrics and Gynaecology last August. Pearce boasted two co-authors: a more junior person than he and the head of his laboratory, Professor Geoffrey Chamberlain. Chamberlain was editor-in-chief of the journal in which Pearce's account of his surgery was published, but he resigned earlier this year. (Honourably, he also then resigned as president of the professional qualifying college to which the journal belongs.) Throughout the affair, Chamberlain has insisted that he knew nothing of the details of the surgical procedure that Pearce had reported, and that he had agreed that his name should be added to the published paper "as a courtesy".

"There's the rub" (to quote Shakespeare again). For a long time, and certainly since the investigation by Ned Feder and Walter W. Stewart of the publication habits of the co-authors of Dr John Darsee at the Harvard Medical School and elsewhere (Nature 325, 207-214; 1987), the perils of 'honorary coauthorship' have been plain. Persons whose reputations flourish when they are among the authors of respectable research are damaged if the research turns out to be based on lies. Mostly, of course, the research is passable, if dull, and no harm is done. What should happen when it appears to have been concocted? Given prevailing local conventions, it would be too much to ask that Chamberlain should have joined Pearce in the dock, but he has a residuary responsibility: he should publicly acknowledge that he should not have allowed his name to appear among the authors of a paper in which he now claims (in his own defence) to have played no part. How else will others like him learn prudence?

\section{Masculinity at risk}

The discovery that the major metabolite of DDT may damage male reproduction deserves attention.

IT would be a cruel irony if the introduction of DDT half a century ago turned out to have been responsible for a decline of male fertility worldwide, but that is one reading of the report by W. R. Kelce and colleagues on page 581 of this issue and the accompanying comment (on page 538) by Dr Richard M Sharpe. What emerges is that the major metabolite of DDT, $p, p^{\prime}$-DDE, is a demasculinizing agent. As Sharpe points out, because DDT is long-lived in the environment (and still widely used against malarial mosquitoes) there is at least a possibility that its ubiquity in human fat may be responsible for falling sperm counts and other reported abnormalities of male reproduction. So what should be done?

The first need is for a better understanding. To be sure, that will seem a fatuous opinion to those who will regard the new developments as threats to their personal health and who may also fear that reduced fertility may spell the end of the human race. The plain truth is that it would be more alarming if the recent increase in the rate of occurrence of testicular cancer (which Denmark is taking seriously) were linked with $p, p^{\prime}$-DDE and were the tip of a larger iceberg. But the immediate need, in that context and others, is for a knowledge of whatever relationship there may be between individuals' content of DDT and the risk that they will develop cancer associated with the reproductive system. That will be a difficult, but not an impossible, undertaking.

Meanwhile, there is a need for a certain calm. Panic will not make DDT disappear from the environment. Moreover, this will not be the first occasion when a presumed link between an environmental contaminant and a risk to health has melted away on close investigation. It cannot but be relevant that the most serious burdens on human health at present are the old ones - resurgent malaria, resurgent tuberculosis. It would be self-defeating (and politically impossible) to push for the outright banning of DDT in, say, mosquito control just in case the presumed effects of its metabolites on male fertility are substantiated. But the case for research to be conducted urgently is overwhelming. 